Revista Eletrônica Geografar, Curitiba, v. 2, Resumos do VI Seminário Interno de Pós-Graduação em Geografia, p. 28-28. Junho/2007

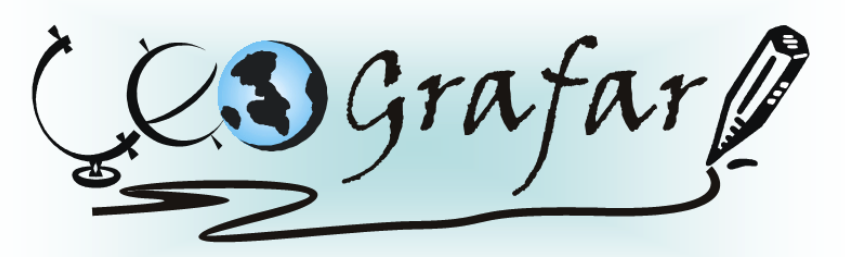

Revista Eletrônica do Programa de Pós-Graduação em Geografia - UFPR

\title{
TIPOLOGIA E TENDÊNCIA CLIMÁTICA DO LITORAL SUL DO BRASIL
}

\author{
FELIPE VANHONI JORGE ${ }^{1}$
}

O estudo do clima ocupa uma posição central e importante no amplo campo da ciência ambiental, pois tem implicações diretas em muitos problemas derivados das relações estabelecidas entre a sociedade e a natureza. O planeta Terra possui muitas e variadas regiões litorâneas, que dependendo de suas posições e dos fatores que as condicionam, apresentam diferentes características climáticas. O clima dessas regiões é determinado por diferentes elementos como a dinâmica da atmosfera, a maritimidade e continentalidade, a localização, o relevo, formação vegetal dentre outros que condicionam os efeitos da temperatura, umidade, pluviosidade, direção dos ventos, pressão atmosférica, radiação, etc. Este trabalho tem como objetivos, analisar as características climáticas do Litoral Sul do Brasil (Paraná, Santa Catarina e Rio Grande do Sul) bem como a análise da tendência climática da região, que vem demonstrando nos últimos anos resultados preocupantes em relação aos efeitos do aquecimento. Para a obtenção de resultados satisfatórios quanto aos objetivos propostos, tomou-se por base uma estruturação na qual o método de pesquisa apresenta os seguintes procedimentos: levantamento bibliográfico acerca do assunto; identificação do comportamento da dinâmica atmosférica da América do Sul, do Brasil e do Litoral Sul, compreendendo os sistemas atmosféricos atuantes na região; identificação da interação entre elementos climáticos e fatores geográficos como o relevo, a proximidade com o oceano e posição latitudinal, além do levantamento e tratamento estatístico, gráfico e espacial de dados climáticos obtidos junto ao INMET (Instituto Nacional de Meteorologia), IAPAR (Instituto Agronômico do Paraná), SUDERHSA (Superintendência de Desenvolvimento de Recursos Hídricos e Saneamento Ambiental do Paraná), FEPAGRO (Fundação Estadual de Pesquisa Agropecuária do Rio Grande do Sul), SIMEPAR (Instituto Tecnológico do Paraná) e EPAGRI (Empresa de Pesquisa Agropecuária e Extensão Rural de Santa Catarina).

Palavras-chave: Clima, Litoral e Tendência

${ }^{1}$ Mestrando em Geografia - UFPR - email:_felipevanhoni@yahoo.com.br Orientador: FRANCISCO MENDONÇA 